\title{
Gerd Zacher \\ (Meppen, Alemania, 6 de julio, 1929; Essen, Alemania, 9 de junio, 2014)
}

\author{
por \\ Hanns Stein \\ Facultad de Artes, Universidad de Chile \\ hsteink@gmail.com
}

Gerd Zacher, organista, compositor, musicólogo, pedagogo falleció poco antes de cumplir 85 años. Este extraordinario músico de estatura internacional tuvo también un vínculo con Chile, al que nos referiremos más adelante.

Zacher nació el 6 de julio de 1929 en Meppen, Alemania. Sus estudios musicales comenzaron a temprana edad y posteriormente se completaron en la Academia de Detmold. Allí conoció a Juan Allende-Blin y al terminar sus estudios en 1954, la familia Allende lo invitó a Chile, donde permaneció durante tres años, como organista y "Kantor" - director de la actividad musical- de la iglesia evangélica alemana de la calle Lota. Durante ese tiempo realizó una intensa actividad como pianista, organista, director de coro y de orquesta junto con contribuir en forma importante al desarrollo musical del país y al conocimiento de corrientes musicales nuevas. Como organista tocó en esos años casi la obra completa de Bach para el instrumento, además de composiciones de Frescobaldi, Scheidt, Sweelinck, Weckmann, Buxtehude, Tunder, Boehm, Telemann, Händel, Mendelssohn, Schumann, Brahms, Reger. Fundó un coro en la iglesia y un conjunto de música antigua con los que interpretó obras, tanto vocales como instrumentales, de Schütz, Gastoldi, Jones, Scheidt, Senfl, Hassler, Locke, Gibbons, Dowland, Praetorius, Krieger, Buxtehude, Purcell, Telemann, Händel.

Como pianista dio a conocer en varios conciertos obras de Hermann Heiss, Boris Blacher, Alban Berg, Aleksandr Skriabin, Alfredo Casella, Olivier Messiaen, Juan Allende-Blin.

Como director hizo, entre otras obras, Dido y Aeneas de Purcell y La historia de la Resurrección de Schütz. Sobre este último concierto escribió Federico Heinlein: "Solo el que conoce la obra y sus problemas sabe lo que significa vencer todas las dificultades existentes y puede entregar una versión tan redonda como la que entregó Zacher en la Iglesia del Salvador. Su formación musicológica unida a un sentir natural sigue el pensamiento de Schütz. Su preparación del coro también fue magistral, es un hábil director y un excelente formador vocal. Así las partes corales tuvieron un acento especial”.

$\mathrm{Al}$ regresar a Alemania Zacher se estableció en Hamburgo, como Kantor y organista de la iglesia luterana de Hamburgo-Wellingsbüttel. A diferencia de otros programas de conciertos de órgano, Zacher incluyó en sus recitales -sin dejar a un lado a Bach-obras de los siglos XIX y XX y también a Mendelssohn. Esto llamaba la atención en esa época de posguerra en la que aún quedaban consecuencias del nazismo y sus definiciones de "arte degenerado", refiriéndose especialmente a obras de autores judíos. Pronto aparecieron en sus programas obras de Milhaud, Satie, Messiaen, Ligeti. Muchos de los compositores importantes de la época, como Ligeti, Cage, Kagel y otros, dedicaron obras a Zacher, quien las ejecutaba en primera audición. Sobre la importancia de la labor de Zacher escribió el 
crítico musical francés Claude Rostand en el Figaro Littéraire: "Así como antes se iba a Lübeck, para escuchar a Buxtehude en las últimas novedades de la técnica de órgano, así ahora de toda Europa se va a escuchar a Zacher en su ritmo mensual de conciertos de órgano, en los que la música contemporánea ocupa un lugar importante".

Como consecuencia de su renombre internacional, basado en conciertos en Europa, Australia y Norteamérica Zacher fue nombrado profesor de la Academia Superior de Música Folkwang de Essen, a cargo del departamento de música sacra evangélica. Allí formó a numerosos organistas que más tarde tuvieron una notable figuración en la vida musical europea.

Las composiciones de Zacher son de diferente carácter. Las hay de contenido sacro, eso sí en un lenguaje contemporáneo avanzado, hay homenajes, a modo de ejemplo a John Cage. Usa una gran cantidad de posibilidades instrumentales y vocales, mucha improvisación y libertad interpretativa. Sus más de cien escritos sobre temas musicales son de una gran profundidad y sabiduría. Hay estudios sobre interpretación de diferentes autores que son sin duda un gran aporte para los intérpretes. Pero Zacher fue también autor de poesía. Fue, en pocas palabras, un intelectual múltiple y de una inmensa creatividad.

Quiero, finalmente, referirme a Gerd Zacher como ser humano y amigo. Conocí a Gerd en 1956, con motivo del estreno de La historia de la Resurrección de Schütz en la iglesia evangélica alemana. Un día recibí una llamada telefónica de un señor Gerd Zacher para invitarme a participar, cantando el papel de Jesús en la mencionada obra. Fue una sorpresa, ya que yo recién daba los primeros pasos en la carrera y desde luego acepté feliz. Fue mi primera experiencia en música sacra. El trabajo con Gerd fue intenso y muy interesante. Detrás de su modestia y su amable sonrisa se escondía un enorme conocimiento el que constituyó un aprendizaje que me marcó de por vida. Allí comenzó una amistad, de mucho significado para mi persona. Poco después Gerd, junto con Juan Allende-Blin, volvió a Alemania. El contacto se restableció 20 años después y entonces tuve la oportunidad de volver a hacer conciertos con Gerd en Alemania y cada uno de ellos constituyó una vivencia para mí.

Nuestro reencuentro tiene una historia curiosa, la cual es un reflejo de la personalidad y del pensamiento de Gerd. Fue a fines de 1976, cuando cayó en mis manos un recorte de un importante diario de Frankfurt, en el que el profesor Gerd Zacher contestaba una carta escrita al diario por un miembro de la colectividad luterana alemana de Chile. En esa carta se acusaba al obispo luterano Frenz, quien jugó un gran papel en la lucha por los derechos humanos al comienzo de la dictadura pinochetista, de haber dividido la colectividad. Zacher caracterizaba, entre otros argumentos, a miembros de la colectividad con la siguiente historia. Escribió Gerd Zacher: "Cuando estrené, bajo el patrocinio del GoetheInstitut, la Historia de la Resurrección de Schütz, cantó el papel de Jesús Hanns Stein, quien, como niño emigró de Praga a Chile. Entonces hubo quejas de miembros de la colectividad, diciendo que demasiados judíos pisaron la iglesia, porque un judío cantaba el Jesús...”.

A raíz de ese recorte de diario nos reencontramos y eso significó la prolongación de una amistad que nunca terminó. Muestra, lo que escribió Gerd, también su carácter y su pensamiento además de una valiente postura democrática y progresista que caracterizó toda su vida y también toda su labor musical. 